\title{
Nuclear organization during in vitro differentiation of porcine mesenchymal stem cells (MSCs) into adipocytes
}

\author{
Joanna Stachecka ${ }^{1}$ - Agnieszka Walczak ${ }^{2}$ - Beata Kociucka ${ }^{1}$ - Błażej Ruszczycki ${ }^{3}$. \\ Grzegorz Wilczyński $^{4} \cdot$ Izabela Szczerbal $^{1}$ (1)
}

Accepted: 8 November 2017 / Published online: 13 November 2017

(c) The Author(s) 2017. This article is an open access publication

\begin{abstract}
Differentiation of progenitor cells into adipocytes is accompanied by remarkable changes in cell morphology, cytoskeletal organization, and gene expression profile. Mature adipocytes are filled with a large lipid droplet and the nucleus tends to move to the cell periphery. It was hypothesized that the differentiation process is also associated with changes of nuclear organization. The aim of this study was to determine the number and distribution of selected components of nuclear architecture during porcine in vitro adipogenesis. The pig is an important animal model sharing many similarities to humans at the anatomical, physiological, and genetic levels and has been recognized as a good model for human obesity. Thus, understanding how cellular structures important for fundamental nuclear processes may be altered during adipocyte differentiation is of great importance. Mesenchymal stem cells (MSCs) were derived from bone marrow (BM-MSCs) and adipose tissue (AD-MSCs) and were cultured for 7 days in the adipogenic medium. A variable differentiation potential of these cell populations towards adipogenic lineage was observed, and
\end{abstract}

Izabela Szczerbal

izabel@up.poznan.pl

1 Department of Genetics and Animal Breeding, Poznan University of Life Sciences, Wolynska 33, 60-637 Poznan, Poland

2 Department of Gene Expression, Institute of Molecular Biology and Biotechnology, Adam Mickiewicz University, Umultowska 89, 61-614 Poznan, Poland

3 Department of Molecular and Cellular Neurobiology, Nencki Institute of Experimental Biology, Polish Academy of Sciences, Pasteura 3, 02-093 Warsaw, Poland

4 Laboratory of Molecular and Systemic Neuromorphology, Nencki Institute of Experimental Biology, Polish Academy of Sciences, Pasteura 3, 02-093 Warsaw, Poland for further study, a comparative characteristic of the nuclear organization in BM-MSCs and AD-MSCs was performed. Nuclear substructures were visualized by indirect immunofluorescence (nucleoli, nuclear speckles, PML bodies, lamins, and HP1 $\alpha$ ) or fluorescence in situ hybridization (telomeres) on fixed cells at 0,3,5, and 7 days of differentiation. Comprehensive characterization of these structures, in terms of their number, size, dynamics, and arrangement in three-dimensional space of the nucleus, was performed. It was found that during differentiation of porcine MSCs into adipocytes, changes of nuclear organization occurred and concerned: (1) the nuclear size and shape; (2) reduced lamin $\mathrm{A} / \mathrm{C}$ expression; and (3) reorganization of chromocenters. Other elements of nuclear architecture such as nucleoli, SC-35 nuclear speckles, and telomeres showed no significant changes when compared to undifferentiated and mature fat cells. In addition, the presence of a low number of PML bodies was characteristic of the studied porcine mesenchymal stem cell adipogenesis system. It has been shown that the arrangement of selected components of nuclear architecture was very similar in MSCs derived from different sources, whereas adipocyte differentiation involves nuclear reorganization. This study adds new data on nuclear organization during adipogenesis using the pig as a model organism.

Keywords Adipogenesis - Chromocenters - Lamin A/C . Nuclear speckles $\cdot$ Nucleoli $\cdot$ Telomeres

\section{Introduction}

The eukaryotic cell nucleus is a complex and highly organized structure responsible for fundamental cellular processes such as transcription, RNA processing, DNA replication, and repair (Schneider and Grosschedl 2007). Even though the 
interchromatin nuclear space does not contain membranes, different nuclear compartments have been recognized (Mao et al. 2011). The compartments, also referred as nuclear bodies, are characterized by a high concentration of a set of specific macromolecules and are visible as distinct nuclear foci at the microscopic level. The best known nuclear bodies include: nucleoli, nuclear speckles, paraspeckles as well as PML (pro-myelocytic leukaemia), Cajal and Polycomb bodies (Spector 2006). Moreover, other discrete sites, termed transcription factories, are present in the nucleus (Jackson et al. 1998; Sutherland and Bickmore 2009). Compartmentalization of the nuclear space creates functionally distinct regions that have a role in genome regulation.

The genome is non-randomly arranged within the threedimensional (3D) nuclear space. Each chromosome occupies a specific location in the interphase nucleus, named chromosome territory (Cremer and Cremer 2010; Meaburn and Misteli 2007). Moreover, both chromatin domains and individual genes display preferential nuclear positions (Bickmore and van Steensel 2013; Ferrai et al. 2010). Various nuclear components such as chromosome territories, subnuclear compartments, or the nuclear envelope contribute to the regulation of gene expression and other cellular functions (Pombo and Dillon 2015). There are many examples showing the relationship between 3D nuclear architecture and the transcriptional status of genes or chromatin domains, including radial positioning of gene-poor and gene-rich chromosome territories towards the nuclear periphery or interior, respectively (Bolzer et al. 2005; Boyle et al. 2001), localization of active/inactive loci within the chromosome territories (Chambeyron and Bickmore 2004; Volpi et al. 2000), spatial clustering of co-regulated genes (Clowney et al. 2012; Schoenfelder et al. 2010), clustering of active genes at nuclear speckles or transcription factories (Brown et al. 2008; Osborne et al. 2004; Papantonis and Cook 2013), and association of transcriptionally inactive DNA regions with the nuclear lamina, nucleolus, or peri-centromeric heterochromatin (Finlan et al. 2008; Reddy et al. 2008; van Koningsbruggen et al. 2010; Wijchers et al. 2015).

Nuclear architecture is dynamic and its reorganization is characteristic for such processes as cell differentiation, proliferation, senescence, or tumorigenesis (Lanctot et al. 2007; Meaburn 2016; Pombo and Dillon 2015). It is also considered as one of the higher-order epigenetic mechanisms important for establishing and maintaining cellular identity during differentiation (Solovei et al. 2016). Adipogenesis, a process of fat cell formation, is a useful model in studies on cellular differentiation. Moreover, comprehending the origin and development of adipocytes is important in view of the increased incidence of obesity and obesity-related disorders in humans (Stephens 2012). Differentiation of progenitor cells into adipocytes is accompanied by remarkable changes in the gene expression profile, cytoskeletal, and extracellular matrix
(ECM) organization and cell morphology (Moreno-Navarrete 2012). Molecular aspects of adipogenesis have been extensively studied in the previous years and a complex network of transcription factors and cell-cycle regulators has been identified (Farmer 2006; Rosen and MacDougald 2006). Recently, the role of nuclear organization during adipocyte differentiation has been focused; however, comparing to other cellular processes, this research is still in infancy (Charo et al. 2016). The most important events taking place during adipogenesis include: reorganization of nuclear lamin (Verstraeten et al. 2011), changes in the nuclear position of chromosome territories and individual genes (Kociucka et al. 2012; Kuroda et al. 2004; Szczerbal et al. 2009), association of adipogenic genes with nuclear speckles (Szczerbal and Bridger 2010), and interactions between selected adipogenic promoters (LeBlanc et al. 2014). These studies were performed using different cell lines and organisms (human, mouse, rat, and pig), and to date, they have provided no comprehensive characterization of nuclear organization for each species. Domestic pig (Sus scrofa) is considered as an attractive large animal model for studies on human obesity in terms of similarities found at the anatomical, physiological, pathological, and genomic levels (Spurlock and Gabler 2008; Stachowiak et al. 2016). Knowledge on cellular and molecular mechanisms associated with adipose tissue development is also needed as far as pig production is concerned, since it may affect neonatal survival, postnatal growth efficiency, and health (Louveau et al. 2016). Moreover, this species has also been recognized as a model organism for interphase genome organization (Foster et al. 2012).

The aim of the presented study was to evaluate global spatial arrangement of selected nuclear substructures during porcine in vitro adipogenesis. It was hypothesized that the dramatic reorganization of cell shape (from fibroblast-like progenitor cells to large, spherical cells with a small rim of cytoplasm, and a flattened peripheral nucleus) during development of fat cells is associated with changes in nuclear organization. We performed a comprehensive analysis of nuclear morphology and several nuclear substructures (nucleoli, nuclear speckles, PML bodies, lamins, and heterochromatin protein 1 alfa-HP1 $\alpha$ and telomeres) in terms of their number, size, and distribution in nuclear space. We established an in vitro system of differentiation of porcine mesenchymal stem cells into adipocytes and applied confocal microscopy and advanced image analysis for study 3D nuclear organization.

\section{Materials and methods}

\section{Cell culture}

Mesenchymal stem cells were derived from the porcine adipose (AD-MSCs_-adipose tissue-derived mesenchymal 
stem cells) and bone-marrow tissues (BM-MSCs-bonemarrow-derived mesenchymal stem cells). MSCs were isolated by the standard methods from subcutaneous fat and leg bones of 3-month-old female Polish Large White pig and were cultured as described earlier by Kociucka et al. (2016). Tissue sample collection was approved by the Local Ethical Commission on Experiments on Animals at the Poznan University of Life Sciences, Poznan, Poland (approval no. 57/2012). Briefly, cells were grown in Advanced DMEM (Advanced Dulbecco's Modified Eagles Medium) (Gibco) supplemented with $10 \%$ (v/v) FBS (fetal bovine serum) (Sigma), $5 \mathrm{ng} / \mathrm{ml}$ FGF-2 (PromoKine), $2 \mathrm{mM}$ L-glutamine (PAA), $1 \mathrm{mM}$ 2-mercaptoethanol (Sigma), $1 \times$ antibiotic antimycotic solution (Sigma), and MEM NEAA (ThermoFisher) at $37{ }^{\circ} \mathrm{C}$ in $5 \% \mathrm{CO}_{2}$. MSCs (mesenchymal stem cells) were propagated by passaging using standard cell culture procedures. When these cells reached confluency, they were cultured in the adipogenic differentiation medium composed of Advanced DMEM (Gibco), with 10\% (v/v) FBS (Sigma), $1 \times$ antibiotic antimycotic solution (Sigma), MEM NEAA (ThermoFisher), 5 ng FGF-2 (PromoKine), $1 \times$ Linoleic Acid Albumin (Sigma), $1 \times$ ITS (Sigma), $1 \mu \mathrm{M}$ Dexamethasone (Sigma), $100 \mu \mathrm{M}$ Indomethacin (Sigma), and $50 \mathrm{mM}$ IBMX (Sigma). The differentiation process lasted for 7 days and was monitored under a phase contrast microscope.

\section{Indirect immunofluorescence}

Immunofluorescence staining was performed on cells grown on glass coverslips at days 0 (undifferentiated MSCs), 3, 5, and 7 of adipogenesis. Cells were fixed in $4 \%$ paraformaldehyde in PBS (w/v) for $10 \mathrm{~min}$ at room temperature and washed three times in PBS buffer. During visualization of PML bodies and SC-35 structures (splicing component of $35 \mathrm{kDa}$ ), cells were permeabilized with $0.1 \%$ Triton $\mathrm{X}-100$ in PBS for $5 \mathrm{~min}$ and then washed three times in PBS. The slides were incubated for $30 \mathrm{~min}$ in $3 \%$ bovine serum albumin dissolved in PBS (w/v) to block nonspecific signals. In the case of visualization PML bodies, blocking was performed with 5\% BSA in PBS (w/v). Primary antibodies anti-lamin A/C (Monoclonal Anti-Lamin A/C produced in mouse, SAB4200236, Sigma), nucleolin (AntiNucleolin antibody produced in rabbit, N2662, Sigma), PML (Monoclonal Anti-PML antibody produced in mouse, P6746, Sigma), SC-35 (Monoclonal anti-Splicing Factor SC-35 antibody produced in mouse, S4045, Sigma), and HP1 $\alpha$ (Anti-HP- $1 \alpha$ antibody produced in rabbit, H2164, Sigma) were diluted $1 / 100$ in $1 \%$ BSA/1× PBS. Cells were incubated with primary antibodies at RT for $1 \mathrm{~h}$, except for antibody anti lamin $\mathrm{A} / \mathrm{C}$, which was incubated overnight at $4{ }^{\circ} \mathrm{C}$. After three washes in PBS, the cells were incubated for $1 \mathrm{~h}$ at room temperature with secondary antibodies diluted
$1 / 200$ in $1 \%$ BSA/1 $\times$ PBS labelled with FITC (monoclonal anti-rabbit IgG ( $\gamma$-chain specific)-FITC antibody produced in mouse, F4151, Sigma) and TRITC (anti-mouse IgG (whole molecule)-TRITC antibody produced in rabbit, T2402, Sigma). After further washing in PBS, the nuclei were counterstained with 4,6-diamidino-2-phenylindole (DAPI) in Vectashield mounting medium (Vector Laboratories).

\section{Fluorescence in situ hybridization (FISH)}

For the FISH procedure, the cells were grown on glass coverslips for $0,3,5$, and 7 days in the adipogenic medium. The cells were then fixed in 4\% paraformaldehyde in PBS buffer (w/v) for $10 \mathrm{~min}$ at room temperature and washed three times in PBS buffer. Hybridization was performed using a commercially available telomere-specific probe (Chrombios, $\mathrm{GmbH}$ ) according to the manufacturer's instructions. The probe and slides were denatured simultaneously on a heat block at $72{ }^{\circ} \mathrm{C}$ for $8 \mathrm{~min}$. Hybridization was performed overnight in a humid chamber at $37^{\circ} \mathrm{C}$. After hybridization, coverslips were washed in $2 \times \mathrm{SSC}$ buffer at RT for $5 \mathrm{~min}$, then in $0.4 \times \mathrm{SSC} / 0.1 \%$ Tween buffer at $70{ }^{\circ} \mathrm{C}$ for $1 \mathrm{~min}$ and in $4 \times \mathrm{SSC} / 0.1 \%$ Tween solution at $45^{\circ} \mathrm{C}$, two times for $5 \mathrm{~min}$. The coverslip were then blocked in 1.5\% BSA for 30 min. Detection was performed using $\mathrm{Cy}^{\circledR} 3$-Streptavidin (GE Healthcare) diluted 1:200. Chromosomes were counterstained with DAPI in the Vectashield medium (Vector Laboratories). To verify specificity of the telomere signals, hybridization was also performed on metaphase spreads derived from the fibroblast cell culture established for the pig as described earlier by Kociucka et al. (2012).

\section{Microscopy and image analysis}

Cells were examined under a phase contrast microscope (TS100 Eclipse, Nikon), a fluorescence microscope (E600 Eclipse, Nikon) and a confocal microscope (LSM 510 Meta, Zeiss). The filters were $560 \mathrm{~nm}$ for TRITC dye, $488 \mathrm{~nm}$ for FITC, and $420 \mathrm{~nm}$ for DAPI. Images from the confocal microscope were taken using the Zeiss LSM 510 3.2 SP1 software under the immersion oil objective $63 \times / 1.4$ NA. The pinhole, filters, and objectives were kept at constant settings throughout the examination of all slides. Z-stacks were formed of approximately $35-50$ pictures taken every $0.3 \mu \mathrm{m}$. Images from fluorescent microscope were taken under the immersion oil objective $100 \times / 1.30$ NA with the LUCIA G software. The capacity of MSCs to differentiate into adipocytes was evaluated by counting cells with lipid droplet in relation with all cells. Visual inspection of images taken by a phase contrast microscope (ten random fields of view using the $20 \times / 0.40$ $\mathrm{Ph} 1$ objective) was used to determine the percentage of differentiated cells. The area of nuclei was measured by 
calculating the nucleus area on fluorescent microscope images of randomly oriented nuclei with area function using the FIJI software. To analyse nuclear volume, Gaussian Blur filter with radius 3.00 was applied on $\mathrm{Z}$-stacks to smooth out the staining pattern. Nuclear volumes were calculated with 3D Object Counter function with a minimal threshold required for nuclei separation in FIJI. To determine nuclear sphericity, TANGO plug in to the FIJI software was used (Ollion et al. 2013). Nuclei were segmented from Z-stacks using Nucleus Edge Detector function and the nuclear volume and surface area was measured. The sphericity was calculated according to equation $\Psi=\frac{\pi^{\frac{1}{3}}\left(6 V_{\mathrm{p}}\right)^{\frac{2}{3}}}{A_{\mathrm{p}}}$, where $V_{\mathrm{p}}$ is volume of particle and $A_{\mathrm{p}}$ is surface area of particle. The value ranges from 0 to 1 , where $\Psi=1$ means an ideal spherical object. To assess the number and location of selected nuclear substructures such as nucleoli, nuclear speckles, PML bodies, and lamins during porcine in vitro adipogenesis, approximately 50 nuclei from AD-MSCs and BM-MSCs were analysed at days $0,3,5$, and 7 of adipogenesis. For measurements of nucleoli and SC-35 speckles, volume single nuclei were segmented from confocal Z-stacks using the 'Segmentation magick' software images as described by Walczak et al. (2013). Segmentation was followed by analysis of nuclear volume, number of nucleoli, mean volume of the nucleoli, total volume of the nucleoli in single nucleus, and total volume of SC 35 speckles in the nucleus. For quantitating the intensity of lamin A/C, images were acquired using the same time exposure. The decrease in lamin abundance was measured using the FIJI software with the fluorescence intensity parameter on confocal microscope sections. Distributions of nucleoli, $\mathrm{SC}-35, \mathrm{HP} 1 \alpha$, and telomeres in interphase nuclei at the 0th, 3rd, 5th, and 7th days of adipogenesis from ADMSCs and BM-MSCs were analysed using TANGO plugin to FIJI. Nuclei were segmented from Z-stacks using nucleus edge detector function, while studied nuclear structures were segmented using hysteresis segmenter function. The radial position of the studied structures was evaluated as described earlier by Kociucka et al. (2012). Briefly, the ratio of measurement distance was calculated, where $R$ was a distance from the signal to the nucleus center divided by distance from the signal to the nuclear border. Value $R>4.45$ was considered as nuclear periphery, $4.45 \geq R \geq 1.37$ was considered as intermediate position, and $R<1.37$ was considered as interior position. Approximately 50 nuclei at each timepoint were analysed. For statistical analysis the ANOVA, Student's $t$ test and test for comparing two binomial parameters were applied. Statistical significance was set at $P \leq 0.05$.

\section{Results}

To analyse the number and distribution of several components of nuclear architecture during porcine adipogenesis, a system of in vitro differentiation of MSCs into adipocytes was used. Two types of MSCs, i.e., cells derived from adipose tissue and bone marrow, were studied. Nuclei and selected substructures of nuclear architecture were examined in cells at $0,3,5$, and 7 days of differentiation (Fig. 1a, b). A variable differentiation potential towards adipogenic lineage was observed. The potential was described as number of cells with lipid droplets compared to all cells $\left(n_{\mathrm{AD}^{-}}\right.$ $\mathrm{MSC}=400, n_{\mathrm{BM}^{-} \mathrm{MSC}}=400$ ) (Fig. 1a, c). The adipose-derived MSCs showed a higher adipogenic differentiation capacity than bone-marrow-derived MSCs. At day 7 of differentiation, $57 \%$ of fully differentiated adipocytes derived from AD-MSCs were observed versus $51 \%$ of adipocytes detected in BM-MSCs (test for comparing two binomial parameters, $P<0.05)$. The established adipocyte differentiation system was useful for study nuclear architecture, since it is well known that changes in global nuclear landscapes are more apparent during the transition from cell precursors towards specialised cell types.

Because formation of mature adipocytes is often associated with the peripheral location of the nucleus as a result of lipid droplet accumulation, we expected that the nucleus shape may change in the course of differentiation. At day 7 of adipogenesis, we observed some cells with flattened nuclei (Fig. 2a). For precise estimation of changes in the size and shape of nuclei during the course of differentiation, we measured nuclear section area, volume, and sphericity. The nuclear section area decreased by approx. $32 \%$ in AD-MSCs and 28\% in BM-MSCs when compared with MSCs $\left(n_{\mathrm{AD}^{-}}\right.$ $\mathrm{MSC}=100, n_{\mathrm{BM}^{-} \mathrm{MSC}}=100$, Student's $t$ test, $P<0.05$ ). No differences were found between AD-MSCs and BM-MSCs $(n=200$, ANOVA, $P>0.05)$ (data not shown). Changes in nuclei volume were more subtle. The decrease of volume was about $15 \%$ when comparing MSCs and cells at 7 days of differentiation in BM-MSC system $(n=82$, Student's $t$ test, $P<0.05$ ). Even if not statistically significant, a similar trend (decrease of nuclear volume by $14 \%$ ) was observed in AD-MSC system ( $n=68$, Student's $t$ test, $P>0.05)$ (Fig. 2b). Nuclei of both undifferentiated cell types (AD-MSC and BM-MSC) were more spherical than nuclei in cells from subsequent days of differentiation. Measurement of a sphericity parameter has shown its decrease during adipogenesis (Fig. 2c). Although a slight change was observed-only about $6.42 \%$ in AD-MSCs and $5.71 \%$ in BM-MSCs, the results were significant due to very small variation inside groups $\left(n_{\mathrm{AD}^{-} \mathrm{MSC}}=346\right.$, ANOVA, $P<0.005, n_{\mathrm{BM}^{-} \mathrm{MSC}}=218$, ANOVA, $P<0.005)$.

Since the proper structure of the nuclear envelope depends on lamins, in the next step, we analysed it by 
a
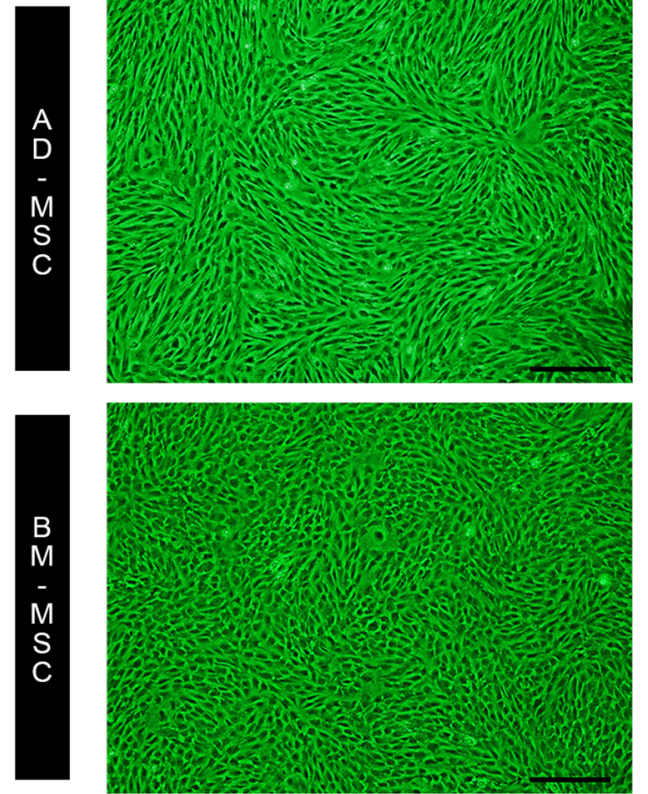

b

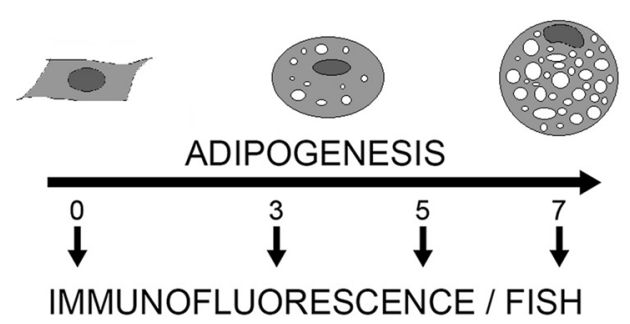

UNDIFFERENTIATED CELLS

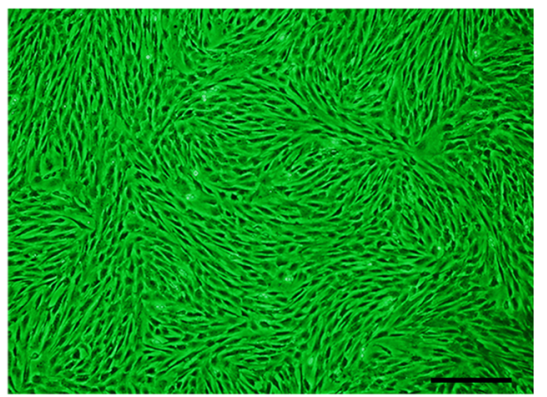

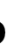

Fig. 1 Characteristics of a porcine in vitro system of differentiation into adipocytes. a Representative images of AD-MSCs and BMMSCs at days 0 and 7 of adipogenesis taken with phase contrast microscope are presented, scale bar: $100 \mu \mathrm{m}$ (two left and two middle pictures) and $50 \mu \mathrm{m}$ (two right pictures). Accumulation of lipid droplets at day 7 of differentiation (adipocytes) is visible. b Diagram shows the experimental scheme. Adipogenesis was carried out by

immunofluorescence (Fig. 3a). A-type lamins were highly abundant in both types of MSCs and its reduction was visible in subsequent days of differentiation (Fig. 3a). The staining patterns were the same in AD-MSCs and BM-MSCs. Cells visualized under a fluorescence microscope have shown pronounced immunostaining throughout the whole nucleus; however, detail confocal microscopy has revealed that lamin $\mathrm{A} / \mathrm{C}$ is located only at nuclear rim. The decrease of lamin $\mathrm{A} / \mathrm{C}$ staining by $17.21 \%$ was visible at day 7 of adipogenesis ( $n=73$, Student's $t$ test, $P<0.05$ ) (Fig. 3b).

Nuclear substructures such as nucleoli, nuclear speckles, and PML bodies were analysed in terms of their number,
ADIPOCYTES
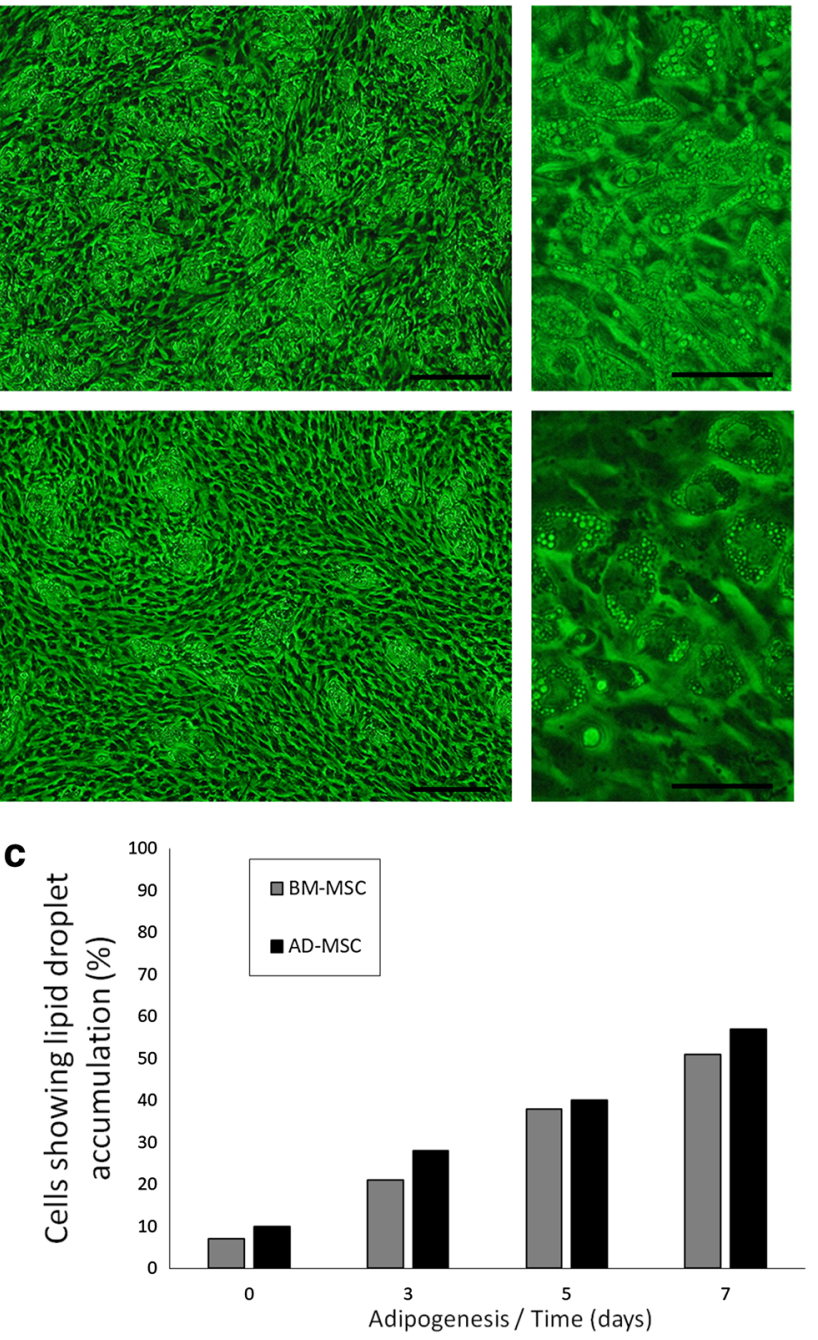

culturing AD-MSCs and BM-MSCs in adipogenic differentiation for 7 days. Components of nuclear architecture were analysed in cells from day 0 (undifferentiated MSC) and at days 3, 5, and 7 of adipogenesis. c Graph shows different adipogenic potentials of AD-MSCs and BM-MSCs. The data are presented as percent of cells showing lipid droplet accumulation in regard to all cells $\left(n_{\mathrm{AD}^{-} \mathrm{MSC}}=400, n_{\mathrm{BM}^{-}}\right.$ $\mathrm{MSC}=400$, test for comparing two binomial parameters, $P<0.05$ )

volume, and distribution in the nucleus. The number of nucleoli did not changed during adipocyte differentiation; however, it was significantly $(n=400$, Student's $t$ test, $P<0.05$ ) higher in AD-MSCs than in BM-MSCs -2 or 3 versus 2 per nucleus (Fig. 4a, b). Despite the differences in nucleoli number, the nucleolar/nuclear volume ratio showed no significant differences between AD-MSCs and BMMSCs $(n=158$, ANOVA, $P>0.05)$ (Fig. 4c). The nucleoli were preferentially located in the nuclear interior during the course of differentiation in both AD-MSCs and BMMSCs $\left(n_{\mathrm{AD}^{-} \mathrm{MSC}}=98, n_{\mathrm{BM}^{-} \mathrm{MSC}}=213\right.$, ANOVA, $\left.P<0.05\right)$ (Fig. 4d). The number of nuclear speckles (SC-35) was not 
a

Adipogenesis

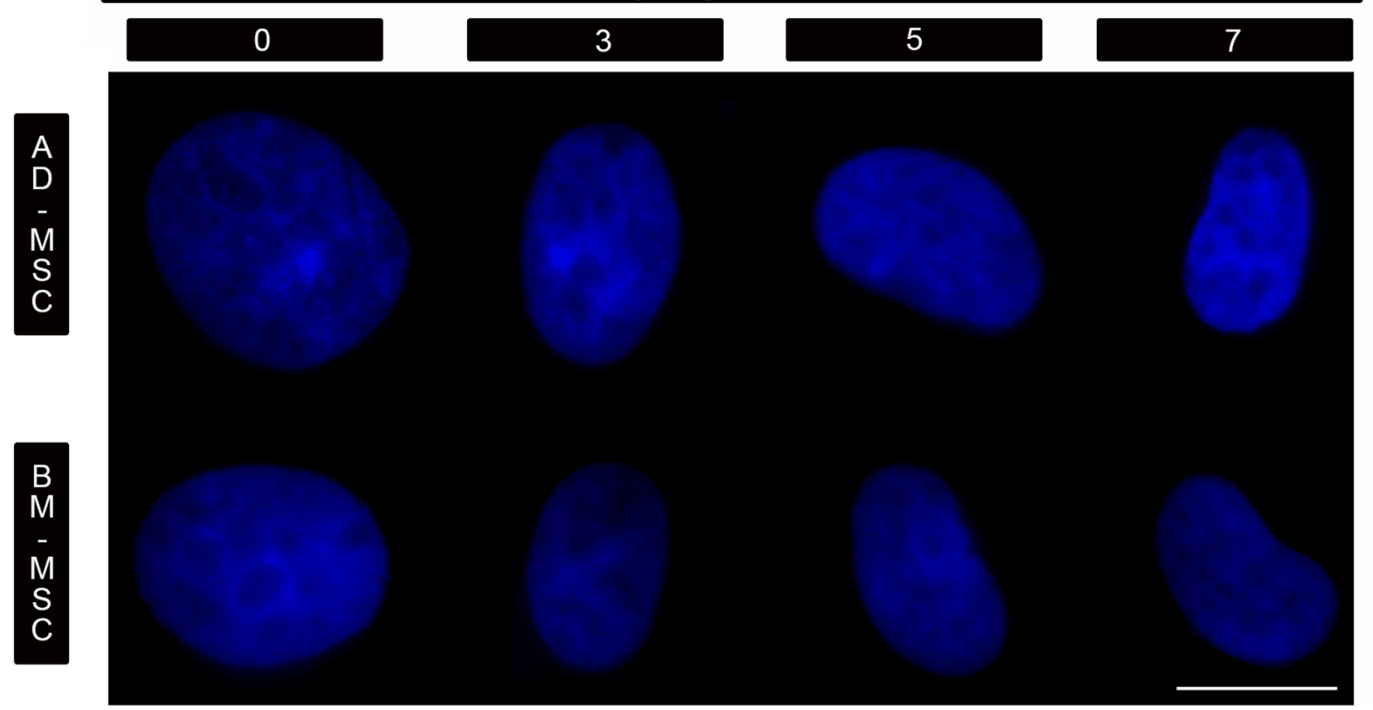

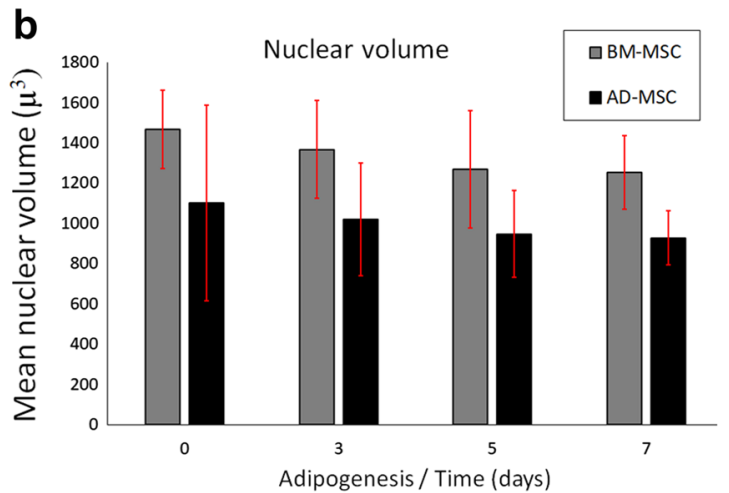

Fig. 2 Nuclear morphology changes during porcine adipogenesis. a Representative images of cell nuclei at days $0,3,5$, and 7 of differentiation in AD-MSCs and BM-MSCs. Nuclei were counterstained with DAPI (blue), scale bar: $10 \mu \mathrm{m}$. Note the more flattened nucleus at day

changed during differentiation when comparing AD-MSCs and BM-MSCs and it ranged between 25 and 35 per nucleus (average number of SC-35 $=27.64, \mathrm{SD}=3.84, n=100$, ANOVA, $P>0.05$, data not shown). No significant differences were found in nuclear speckles/nuclear volume ratio; however, they showed very high variations within groups in both AD-MSC and BM-MSC systems $\left(n_{\mathrm{AD}^{-} \mathrm{MSC}}=99, n_{\mathrm{BM}^{-}}\right.$ ${ }_{\mathrm{MSC}}=99$, ANOVA, $P>0.05$ ) (Fig. 5b). Analysis of nuclear distribution of SC-35 structures has shown its preferential location in intermediate and peripheral parts of nuclei $\left(n_{\mathrm{AD}^{-}}\right.$ ${ }_{\mathrm{MSC}}=264, n_{\mathrm{BM}^{-} \mathrm{MSC}}=218$, ANOVA, $\left.P<0.05\right)($ Fig. 5a, c). PML nuclear bodies were present in MSCs and differentiating cells, with the number 2-3 per nucleus (Fig. 6) and no significant variation in the number was observed in the studied cells (average number of PML bodies $=2.89, n=100$, $\mathrm{SD}=0.25$, ANOVA, $P>0.05$, data not shown). Since PML

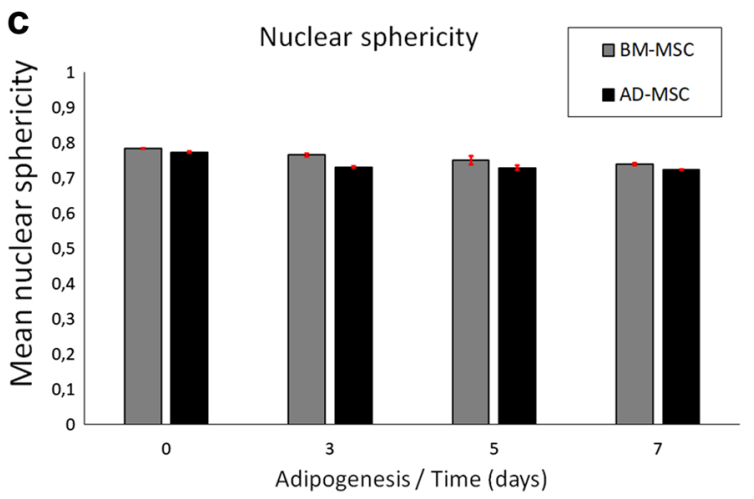

7. b Graph shows changes in nuclear volume $\left(n_{\mathrm{BM}^{-} \mathrm{MSC}}=82\right.$, Student's $t$ test, $P<0.05 ; n_{\mathrm{AD}}{ }^{-} \mathrm{MSC}=68$, Student's $t$ test, $\left.P>0.05\right)$. c Graph shows changes in nuclei sphericity $\left(n_{\mathrm{AD}^{-} \mathrm{MSC}}=346, n_{\mathrm{BM}^{-} \mathrm{MSC}}=218\right.$, error bars show SD, ANOVA, $P<0.005$ )

bodies were visible as very tiny, punctate structures, their evaluation in 3D nuclear space was very difficult, and thus, the distribution analysis was not performed.

To determine whether global chromosome rearrangements take place during porcine adipogenesis, the distribution of telomeres and heterochromatin protein 1 alpha (HP1 $\alpha$ ) was studied. Telomeres were visualized by FISH approach and 76 telomeric signals were expected in the interphase nucleus. However, the observed number of signals was lower at approx. $43 \pm 6$, which suggests clustering of adjacent telomeres (average number of telomeres $=43$, $\mathrm{SD}=5.75$, comparison of number of telomeres between days 0 and 7 of adipogenesis in AD-MSC and BM-MSC systems: $n=132$, Student's $t$ test, $P>0.05$ ). The telomeres were evenly distributed throughout the nucleus and no differences were observed when comparing MSCs 
Fig. 3 Reorganization of nuclear lamin $\mathrm{A} / \mathrm{C}$ during porcine adipogenesis. The decrease in abundance of lamins was detected by indirect immunofluorescence. Representative images of anti-lamin $\mathrm{A} / \mathrm{C}$ staining (red) in nuclei derived from BM-MSCs taken under a fluorescence microscope (a, top) and in nuclei derived from AD-MSCs taken under a confocal microscope (a, bottom) are shown. Nuclei were counterstained with DAPI (blue), scale bar: $10 \mu \mathrm{m}$. Note that confocal microscopy demonstrated the lamin $\mathrm{A} / \mathrm{C}$ signal only at the nuclear rim. b Graph shows the decrease of fluorescence intensity of lamin A/C staining in subsequent days of differentiation of AD-MSCs $(n=135$, error bars show SD, Student's $t$ test, $P<0.05$ ) a

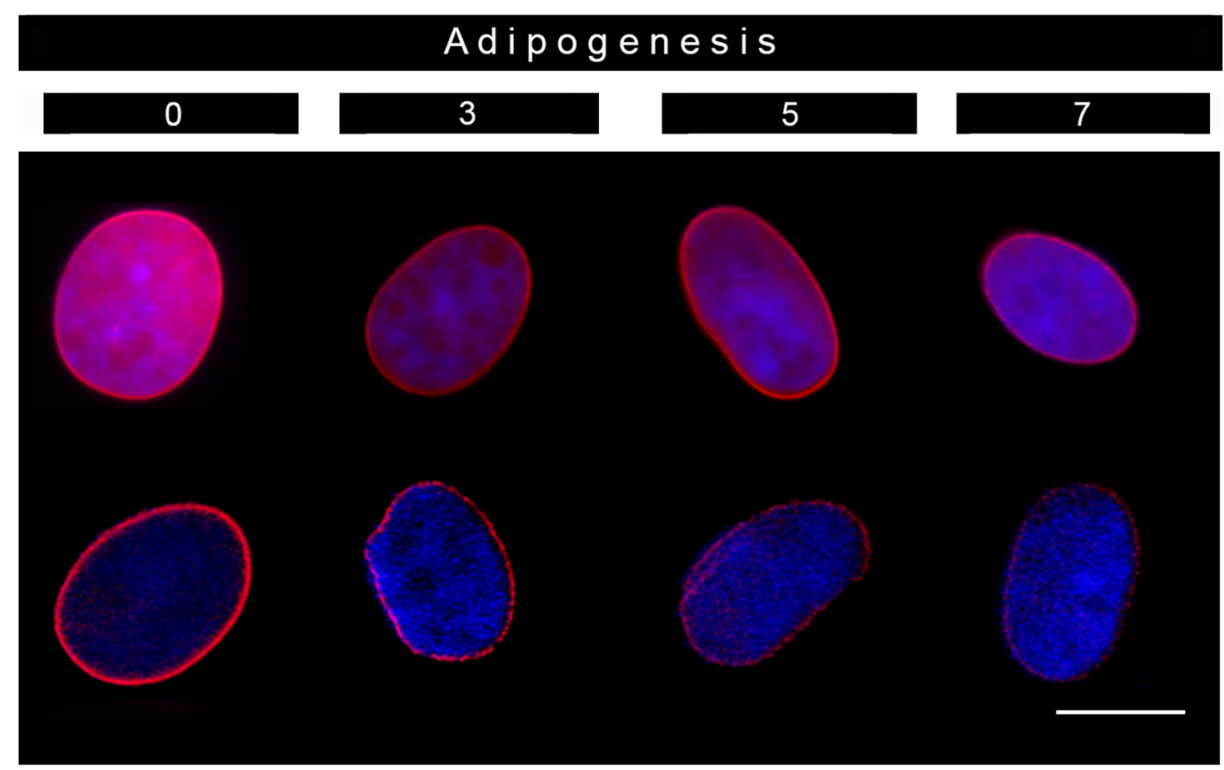

b

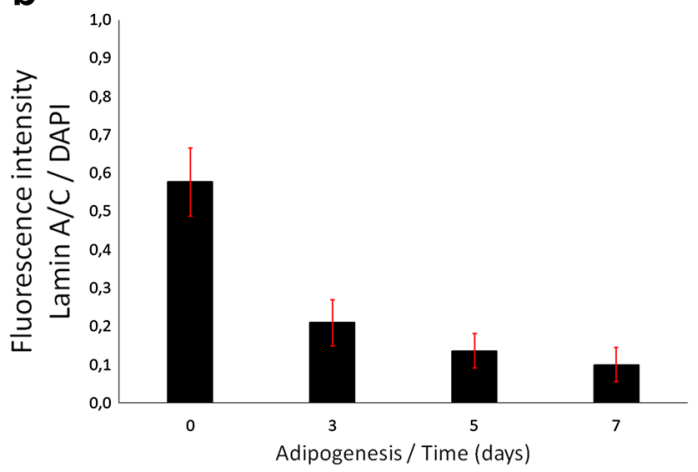

with differentiated cells $\left(n_{\mathrm{AD}^{-} \mathrm{MSC}}=60, n_{\mathrm{BM}^{-} \mathrm{MSC}}=72\right.$, ANOVA, $P>0.05$ ) (Fig. 7a, b). The HP1 $\alpha$, a component of pericentric heterochromatin, formed distinct foci in the nucleus and was found to colocalize with chromocenters. Strong-staining foci of heterochromatin were observed in MSCs, while in maturing adipocytes, the foci were more diffused (Fig. 8a). Measurement of HP1 $\alpha$ signals volume has shown its reduction during the course of differentiation $\left(n_{\mathrm{AD}^{-} \mathrm{MSC}}=87, n_{\mathrm{BM}^{-} \mathrm{MSC}}=126\right.$, ANOVA, $\left.P<0.05\right)$ (Fig. 8b). In undifferentiated cells and in cells from the first days of differentiation, the HP1 $\alpha$ signals were heterogeneous (visible as large error bars on Fig. 8b-day 0 and day 3), with predominant discrete and bright clumps but also with visible many punctate foci dispersed throughout the nucleus. Within subsequent days of differentiation, heterochromatin clumps have disappeared and only punctate signals were observed at day 7 of adipogenesis. The HP1 $\alpha$ signals were preferentially located in nuclear interior and intermediate part of the nucleus $\left(n_{\mathrm{AD}^{-} \mathrm{MSC}}=87\right.$, $n_{\mathrm{BM}^{-} \mathrm{MSC}}=126$, ANOVA, $\left.P<0.05\right)($ Fig. $8 \mathrm{c}$ ).

\section{Discussion}

In the presented study, we performed a comparative characteristic of the nuclear organization in porcine mesenchymal stem cells derived from bone marrow and adipose tissue and during their differentiation into adipocytes. Despite the fact that these two cell types showed a different capacity for adipogenic differentiation, they were very similar in terms of the number and distribution of selected elements of nuclear architecture. Differences were observed when comparing mesenchymal stem cells and mature adipocytes. The main features distinguishing aforementioned cells were the shape and size of their nuclei. In MSCs, they were larger and more spherical, while in adipocytes, an ellipsoid shape was observed. The occurrence of changes in the nuclear shape during differentiation and maturation is a well-known phenomenon (Skinner and Johnson 2017), with extreme examples concern lobulated nuclei in neutrophils (Carvalho et al. 2015) or elongated nuclei in spermatids (Lin et al. 2016). This suggests that changes in the nuclear shape and structure 
a

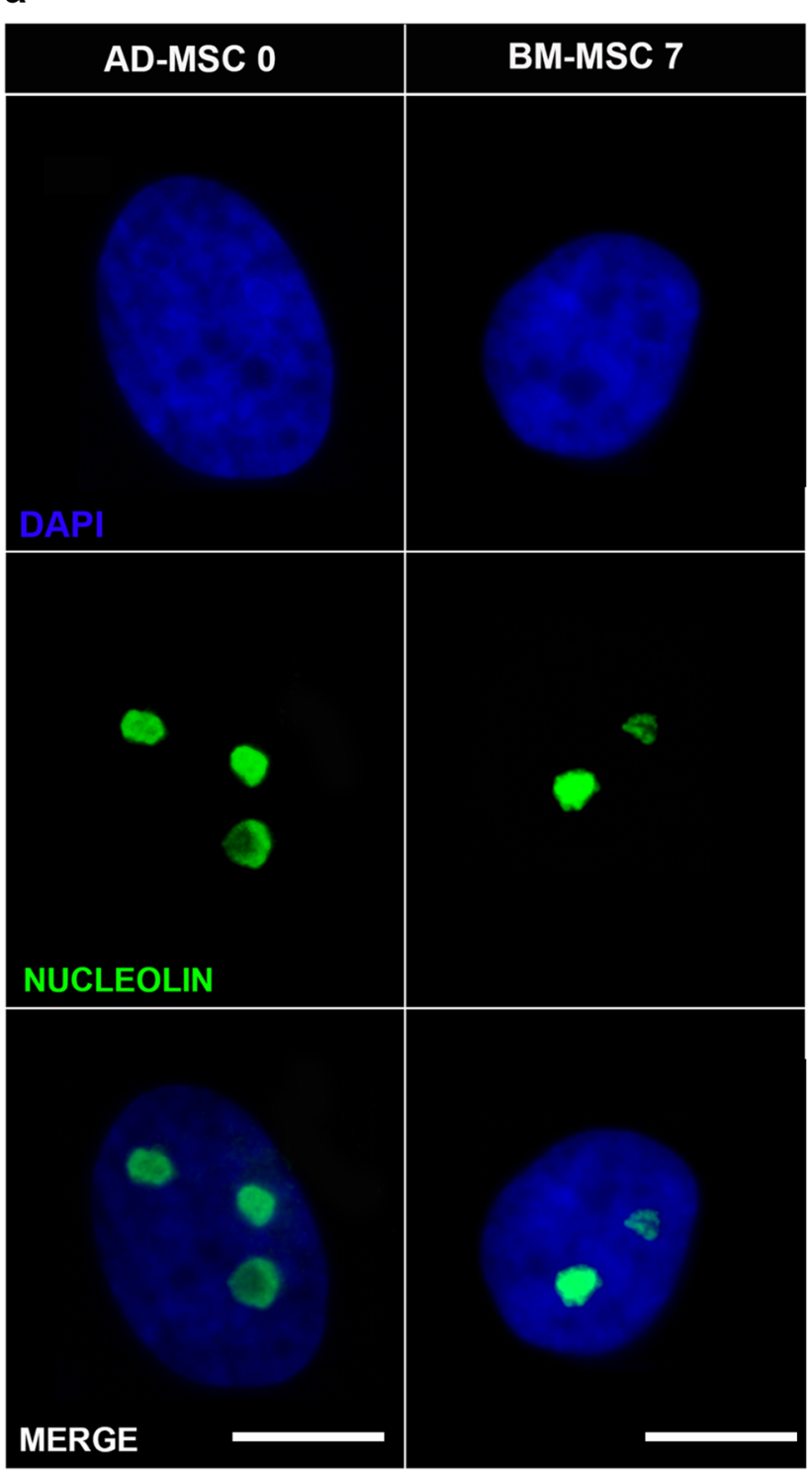

Fig. 4 Characteristics of nucleoli in porcine adipogenesis system in vitro. Anti-nucleolin immunostaining revealed three nucleoli (green) in AD-MSCs (a, left) and two in BM-MSCs (a, right). Nuclei were counterstained with DAPI (blue), scale bar: $10 \mu \mathrm{m}$. No significant changes were observed in nucleolar number (b) and volume

during cell specialization are related to the function and phenotype of the cell (Dahl et al. 2008).

The A-type lamins play an important role in maintaining the proper shape and structure of the nucleus (Lammerding et al. 2006). Beyond their structural function, lamins also participate in cell proliferation and differentiation through regulation of transcription and chromatin organization (Dechat et al. 2008). It has been previously reported that b Number of nucleoli in interphase nuclei
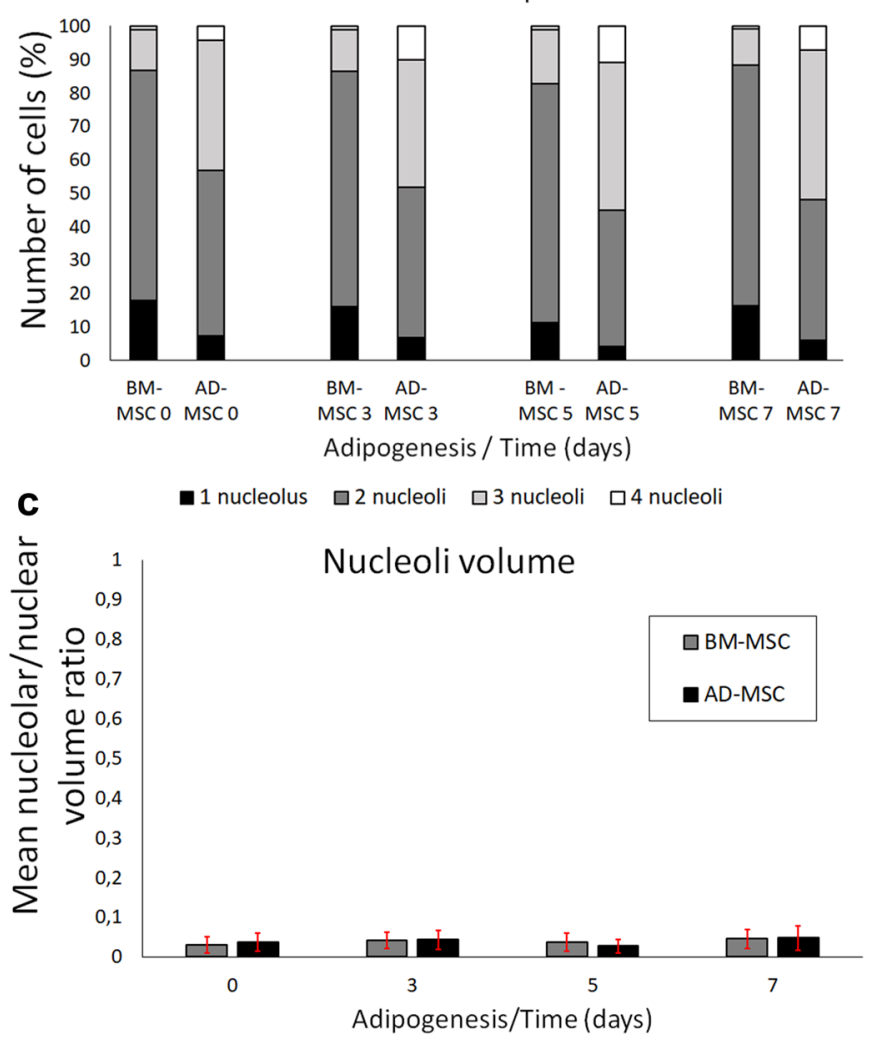

d

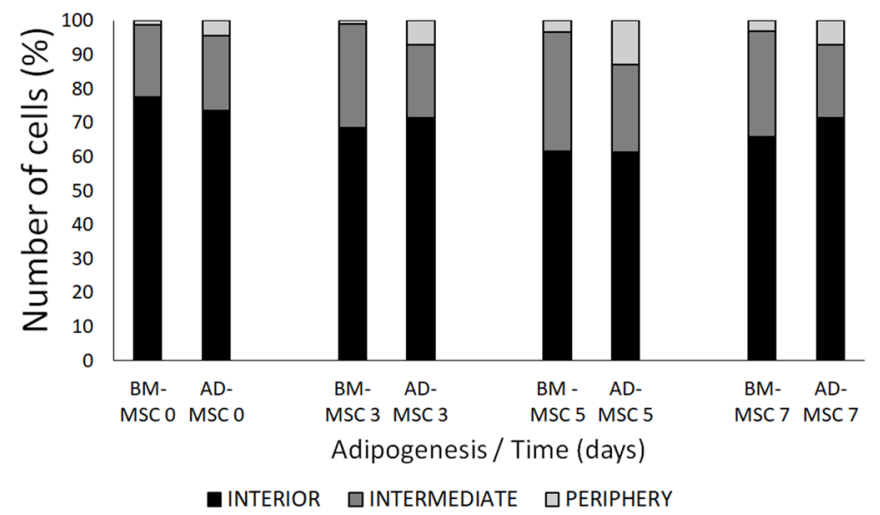

(c) during differentiation ( $n=158$, error bars show SD, ANOVA, $P>0.05$ ). d Nucleoli were preferentially located in interior and intermediate parts of nucleus $\left(n_{\mathrm{AD}^{-} \mathrm{MSC}}=98, n_{\mathrm{BM}^{-} \mathrm{MSC}}=213\right.$, ANOVA, $P<0.05)$

reduced expression of lamin A/C facilitates adipogenic differentiation of mesenchymal stem cells by regulating the Wnt/ $\beta$-catenin signaling pathway (Bermeo et al. 2015). Reorganization of the nuclear lamina during adipocyte formation has been well described in the mouse and human model systems (Verstraeten et al. 2011). Our study confirms that a decrease of lamin $\mathrm{A} / \mathrm{C}$ levels is also characteristic of porcine adipogenesis. Since lamins $\mathrm{A}$ and $\mathrm{C}$ are considered 
a

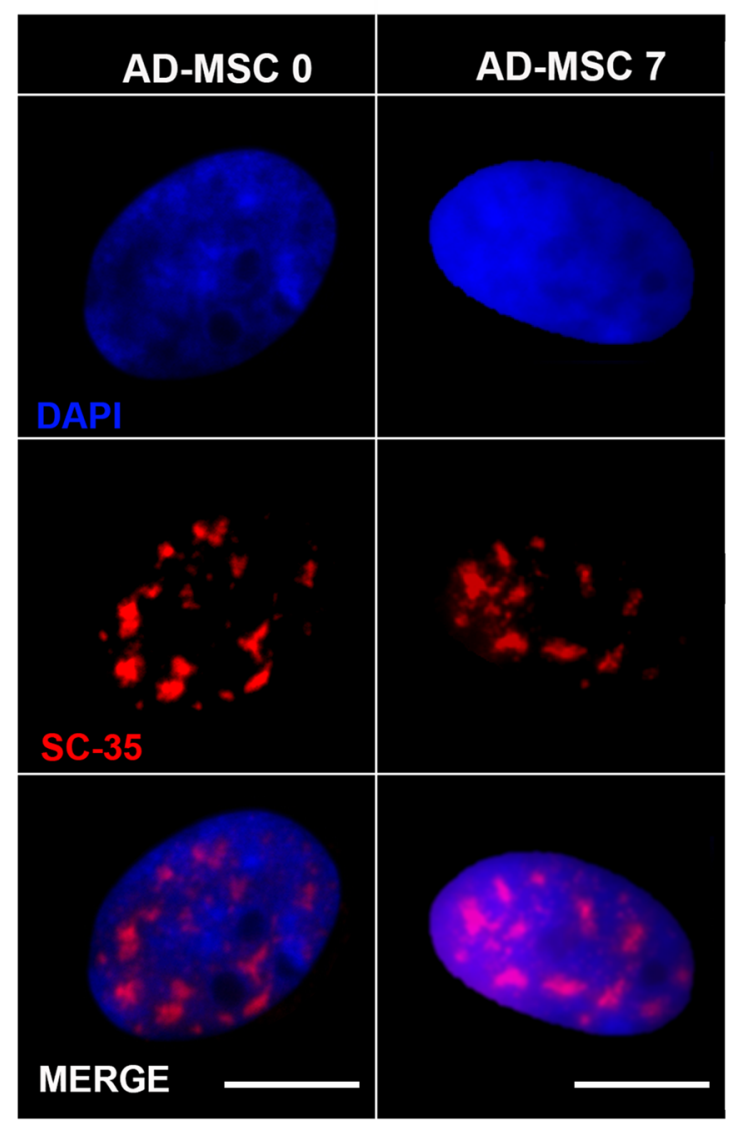

Fig. 5 Nuclear speckles during porcine adipogenic differentiation. a Presence of nuclear speckles (red) in AD-MSCs at days 0 and 7 of differentiation revealed by immunofluorescence with anti-SC35 antibody. Nuclei were counterstained with DAPI (blue), scale bar: $10 \mu \mathrm{m}$. b Volume of SC-35 structures has not changed significantly during

to be important elements influencing nuclear stiffness, their reduced levels lead to increased plasticity of the nucleus, which, as it was observed in the case of the flattened nuclei by lipid droplets in our porcine adipogenesis system, or in human adipose tissue (Verstraeten et al. 2011).

Changes in nuclear shape and plasticity, characteristic of the differentiation process, may involve reorganization of nuclear architecture. Our analysis of the number, size, and distribution of nucleoli has shown no differences when comparing porcine MSCs and mature adipocytes. In contrast, during keratinocyte differentiation, the nucleoli decreased in number and were repositioned towards the nuclear interior (Gdula et al. 2013). The observed increased number of nucleoli in AD-MSCs rather than in BM-MSCs could be associated with a higher metabolic activity of the ADMSCs. It has been reported that adipose tissue-derived MSCs are more metabolically active than BM-MSCs due to the elevated secretion of cytokines (Melief et al. 2013). In addition, a larger size or number of nucleoli were found in
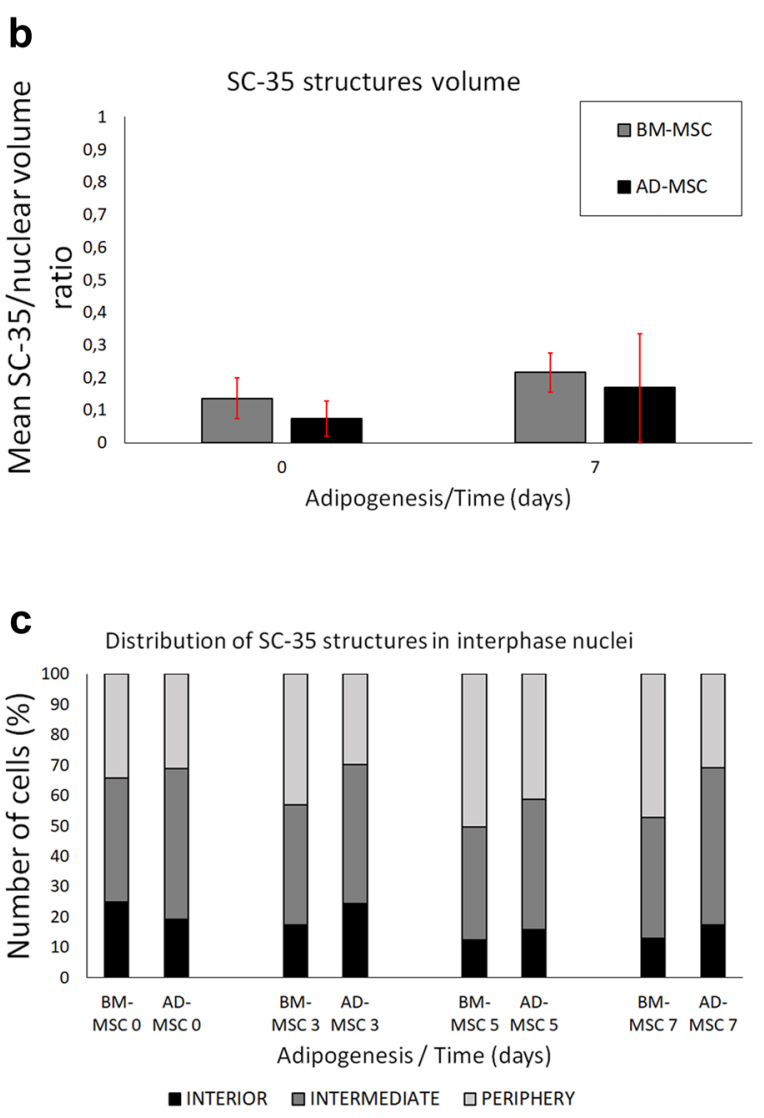

in vitro adipogenesis $\left(n_{\mathrm{AD}^{-} \mathrm{MSC}}=99, n_{\mathrm{BM}^{-} \mathrm{MSC}}=99\right.$, error bars show SD, ANOVA, $P>0.05)$. c SC-35 structures preferentially occupied intermediate and peripheral parts of nucleus $\left(n_{\mathrm{AD}^{-} \mathrm{MSC}}=264, n_{\mathrm{BM}^{-}}\right.$ MSC $=218$, ANOVA, $P<0.05)$

other types of active cells, including tumor cells, which is related to their high cell proliferation rate (Sirri et al. 2008). We observed no reorganization during the differentiation of other nuclear substructures, such as nuclear speckles and PML bodies. Similarly, no differences in the number and distribution of SC-35 nuclear speckles were observed when two timepoints (day 0 and day 14) of porcine adipogenesis were compared (Szczerbal and Bridger 2010). In normal cells, the number of PML bodies ranges from 1 to 30 and depends on cell type and its cycle phase (Bernardi and Pandolfi 2007). We detected only 2-3 PML bodies per nucleus in the studied cells. These results are in agreement with other molecular studies on PML showing that the deficiency of PML increases adipogenesis (Kim et al. 2011), while its increased expression promotes osteogenic differentiation (Sun et al. 2013).

Telomere positioning may reflect arrangements of chromosomes in the nucleus. Usually, telomeres are evenly distributed in mammalian cell nuclei; however, in some cell 


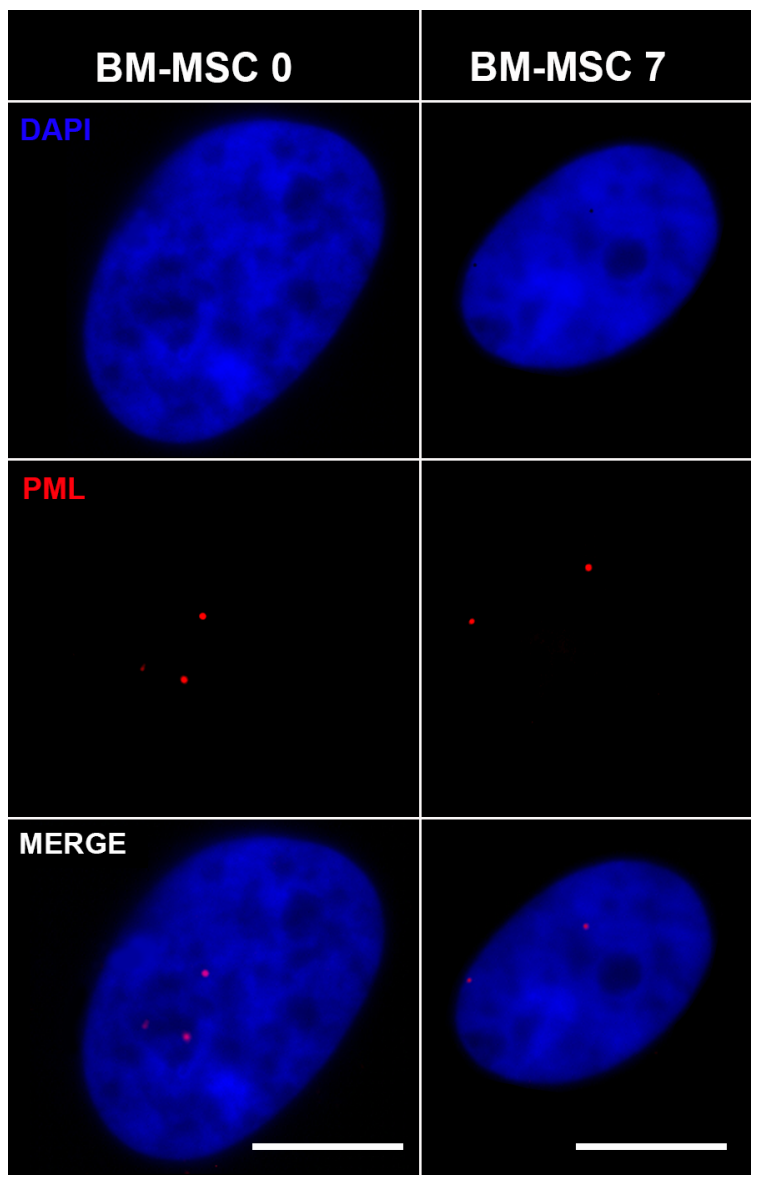

Fig. 6 PML bodies visualized by indirect immunofluorescence with anti-PML antibody (red) at days 0 and 7 of differentiation in BMMSCs. Nuclei were counterstained with DAPI (blue), scale bar: $10 \mu \mathrm{m}$. Predominantly 2-3 PML bodies were observed in the studied porcine adipogenesis system

types (e.g., sperm), they are preferentially located in the nuclear periphery (Mudrak et al. 2005). In our study, we observed no changes in the number or distribution of telomeres when MSCs and mature adipocytes were compared. Telomere clustering was detected in both undifferentiated and terminally differentiated cells. It seems that this is a characteristic feature of interphase nuclei arrangements, since it was observed in many cell types, including lymphocytes, neutrophils, and cancer cells (Chuang et al. 2004; Weierich et al. 2003; Yerle-Bouissou et al. 2009). Since mammalian HP1 $\alpha$ localizes with pericentromeric heterochromatin in the interphase, we also analysed the distribution of chromocenters. They were well visible in MSCs and become more diffuse in the course of the differentiation. Reorganization of chromocenters was also observed during myogenesis, where their number in cell precursors was higher than in the myotubes; however, their size increased as an effect of clustering (Brero et al. 2005). A single, very large, centrally located chromocenter was found in rod photoreceptor cells a

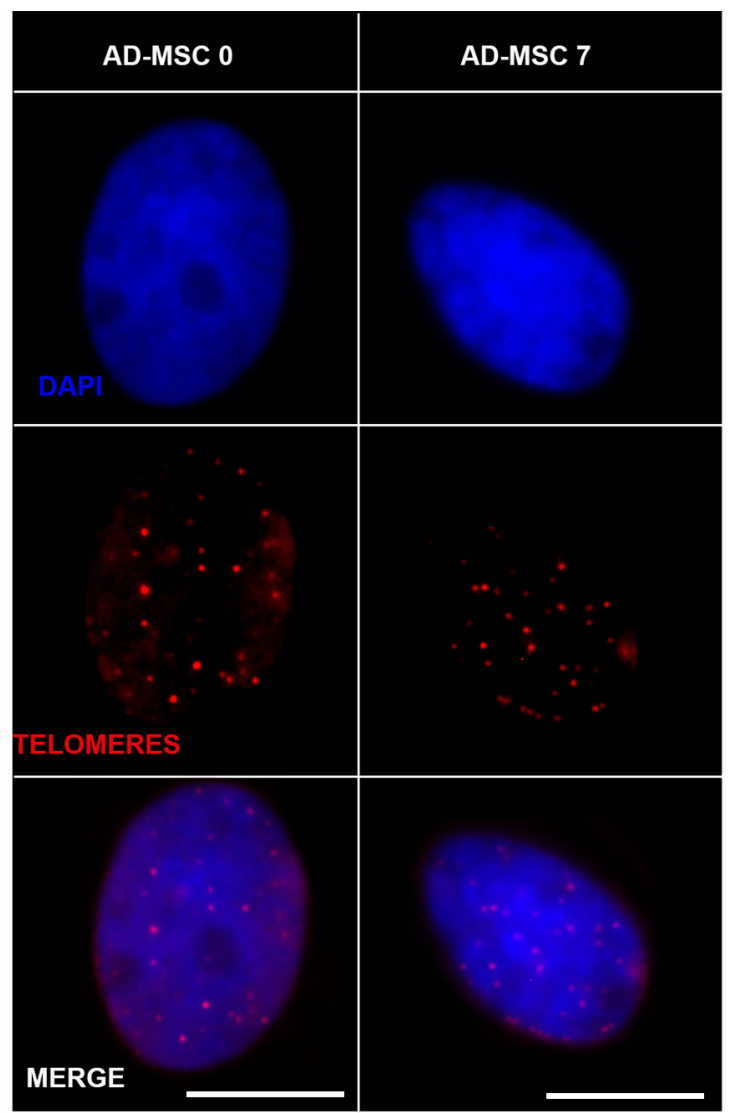

b Distribution of telomeres in interphase nuclei

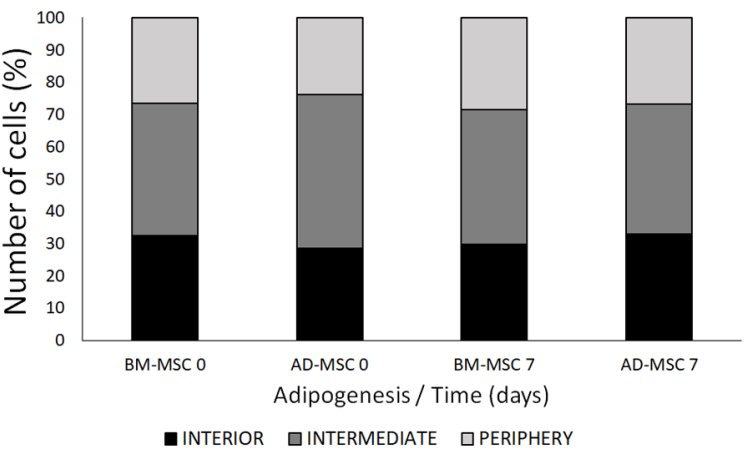

Fig. 7 Distribution of telomeres during porcine adipogenesis. a Telomeres (red) were visualized by FISH approach in AD-MSCs at days 0 and 7 of differentiation. Nuclei were counterstained with DAPI (blue), scale bar: $10 \mu \mathrm{m}$. Note telomere clustering events (bigger and brighter foci) characteristic to interphase. b Telomeres were evenly distributed through nuclear space during differentiation $\left(n_{\mathrm{AD}^{-}}\right.$ $\mathrm{MSC}=60, n_{\mathrm{BM}^{-} \mathrm{MSC}}=72$, error bars show SD, ANOVA, $P>0.05$ )

(Solovei et al. 2009). These results indicated that terminal differentiation is accompanied by a reorganization of pericentric heterochromatin. It has also been demonstrated that distribution of heterochromatin is dependent of the state of cell proliferation-diffuse nuclear staining of HP1 $\alpha$ was characteristic for non-dividing cells (Grigoryev et al. 2004; Naetar et al. 2007). 
a
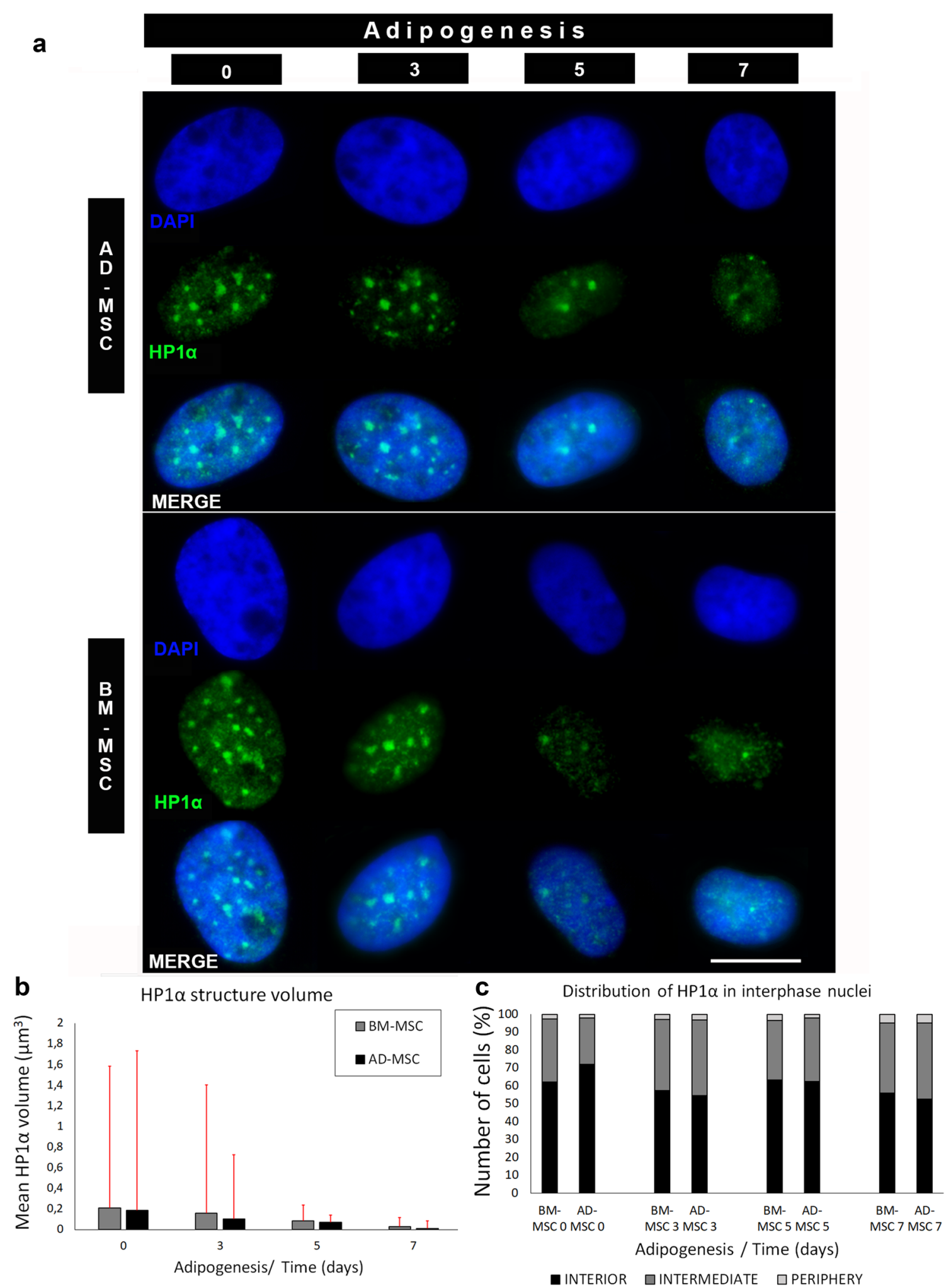

Fig. 8 Reorganization of chromocenters during porcine adipogenesis. a Indirect immunofluorescence with the use of anti-HP1 $\alpha$ antibody (green) was performed on AD-MSCs and BM-MSCs cells at days $0,3,5$, and 7 of adipogenesis. Nuclei were counterstained with DAPI (blue), scale bar: $10 \mu \mathrm{m}$. Diffuse distribution of heterochromatin domains at days 5 and 7 of adipogenesis was observed. b Graph shows decrease volume of HP1 $\alpha$ structures during differen-

tiation $\left(n_{\mathrm{AD}^{-} \mathrm{MSC}}=87, n_{\mathrm{BM}^{-} \mathrm{MSC}}=126\right.$, error bars show SD, ANOVA, $P<0.05$ ). Note heterogeneity of structures (clumped and punctate foci) at days 0 and 3 of adipogenesis. $\mathbf{c}$ Graph shows distribution of the HP1 $\alpha$ foci in nuclear space, with preferential location in the central and intermediate parts of nuclei $\left(n_{\mathrm{AD}^{-} \mathrm{MSC}}=87, n_{\mathrm{BM}^{-} \mathrm{MSC}}=126\right.$, ANOVA, $P<0.05)$ 


\section{Conclusion}

Our study showed that during differentiation of porcine mesenchymal, stem cells (AD-MSCs and BM-MSCs) into adipocytes changes of nuclear organization take place and concern: (1) the nuclear size and shape; (2) reduced lamin $\mathrm{A} / \mathrm{C}$ expression; and (3) reorganization of chromocenters. In addition, the presence of a low number of PML bodies is characteristic for adipogenic differentiation system. Other elements of nuclear architecture, such as nucleoli, SC-35 nuclear speckles, and telomeres, showed no significant changes when comparing undifferentiated cells and mature adipocytes. Obtained results add new data on the nuclear organization during the formation of adipocytes in pigs. Studies on different model organisms are necessary to provide more in depth insight into the manner in which the nuclear architecture contributes to the functioning of fat cells.

Acknowledgements The authors would like to thank Dr. Tatiana Flisikowska (Technische Universität München, München, Germany) for her help in work with porcine mesenchymal stem cells. This work was supported by the National Science Centre in Poland-Grant 2012/07/E/NZ9/02573.

\section{Compliance with ethical standards}

Conflict of interest The authors declare that they have no conflict of interest.

Open Access This article is distributed under the terms of the Creative Commons Attribution 4.0 International License (http://creativecommons.org/licenses/by/4.0/), which permits unrestricted use, distribution, and reproduction in any medium, provided you give appropriate credit to the original author(s) and the source, provide a link to the Creative Commons license, and indicate if changes were made.

\section{References}

Bermeo S, Vidal C, Zhou H, Duque G (2015) Lamin A/C acts as an essential factor in mesenchymal stem cell differentiation through the regulation of the dynamics of the $\mathrm{Wnt} /$ beta-Catenin pathway. J Cell Biochem 116:2344-2353. https://doi.org/10.1002/jcb.25185

Bernardi R, Pandolfi PP (2007) Structure, dynamics and functions of promyelocytic leukaemia nuclear bodies. Nat Rev Mol Cell Biol 8:1006-1016. https://doi.org/10.1038/nrm2277

Bickmore WA, van Steensel B (2013) Genome architecture: domain organization of interphase chromosomes. Cell 152:1270-1284. https://doi.org/10.1016/j.cell.2013.02.001

Bolzer A, Kreth G, Solovei I, Koehler D, Saracoglu K, Fauth C, Müller S, Eils R, Cremer C, Speicher MR, Cremer T (2005) Threedimensional maps of all chromosomes in human male fibroblast nuclei and prometaphase rosettes. PLoS Biol 3:e157. https://doi. org/10.1371/journal.pbio.0030157

Boyle S, Gilchrist S, Bridger JM, Mahy NL, Ellis JA, Bickmore WA (2001) The spatial organization of human chromosomes within the nuclei of normal and emerin-mutant cells. Hum Mol Genet $10: 211-219$
Brero A, Easwaran HP, Nowak D, Grunewald I, Cremer T, Leonhardt H, Cardoso MC (2005) Methyl CpG-binding proteins induce large-scale chromatin reorganization during terminal differentiation. J Cell Biol 169:733-743. https://doi.org/10.1083/ jcb. 200502062

Brown JM, Green J, das Neves RP, Wallace HA, Smith AJ, Hughes J, Gray N, Taylor S, Wood WG, Higgs DR, Iborra FJ, Buckle VJ (2008) Association between active genes occurs at nuclear speckles and is modulated by chromatin environment. J Cell Biol 182:1083-1097. https://doi.org/10.1083/jcb.200803174

Carvalho LO, Aquino EN, Neves AC, Fontes W (2015) The neutrophil nucleus and its role in neutrophilic function. J Cell Biochem 116:1831-1836. https://doi.org/10.1002/jcb.25124

Chambeyron S, Bickmore WA (2004) Chromatin decondensation and nuclear reorganization of the HoxB locus upon induction of transcription. Genes Dev 18:1119-1130. https://doi.org/10.1101/ $\operatorname{gad} .292104$

Charo NL, Rodriguez Ceschan MI, Galigniana NM, Toneatto J, Piwien-Pilipuk G (2016) Organization of nuclear architecture during adipocyte differentiation. Nucleus 7:249-269. https://doi. org/10.1080/19491034.2016.1197442

Chuang TC, Moshir S, Garini Y, Chuang AY, Young IT, Vermolen B, van den Doel R, Mougey V, Perrin M, Braun M, Kerr PD, Fest T, Boukamp P, Mai S (2004) The three-dimensional organization of telomeres in the nucleus of mammalian cells. BMC Biol 2:12. https://doi.org/10.1186/1741-7007-2-12

Clowney EJ, LeGros MA, Mosley CP, Clowney FG, MarkenskoffPapadimitriou EC, Myllys M, Barnea G, Larabell CA, Lomvardas S (2012) Nuclear aggregation of olfactory receptor genes governs their monogenic expression. Cell 151:724-737. https://doi. org/10.1016/j.cell.2012.09.043

Cremer T, Cremer M (2010) Chromosome territories. Cold Spring Harb Perspect Biol 2:a003889. https://doi.org/10.1101/cshperspect.a003889

Dahl KN, Ribeiro AJ, Lammerding J (2008) Nuclear shape, mechanics, and mechanotransduction. Circ Res 102:1307-1318. https://doi. org/10.1161/circresaha.108.173989

Dechat T, Pfleghaar K, Sengupta K, Shimi T, Shumaker DK, Solimando L, Goldman RD (2008) Nuclear lamins: major factors in the structural organization and function of the nucleus and chromatin. Genes Dev 22:832-853. https://doi.org/10.1101/ gad. 1652708

Farmer SR (2006) Transcriptional control of adipocyte formation. Cell Metab 4:263-273. https://doi.org/10.1016/j.cmet.2006.07.001

Ferrai C, de Castro IJ, Lavitas L, Chotalia M, Pombo A (2010) Gene positioning. Cold Spring Harb Perspect Biol 2:a000588. https:// doi.org/10.1101/cshperspect.a000588

Finlan LE, Sproul D, Thomson I, Boyle S, Kerr E, Perry P, Ylstra B, Chubb JR, Bickmore WA (2008) Recruitment to the nuclear periphery can alter expression of genes in human cells. PLoS Genet 4:e1000039. https://doi.org/10.1371/journal.pgen.1000039

Foster HA, Griffin DK, Bridger JM (2012) Interphase chromosome positioning in in vitro porcine cells and ex vivo porcine tissues. BMC Cell Biol 13:30. https://doi.org/10.1186/1471-2121-13-30

Gdula MR, Poterlowicz K, Mardaryev AN, Sharov AA, Peng Y, Fessing MY, Botchkarev VA (2013) Remodeling of three-dimensional organization of the nucleus during terminal keratinocyte differentiation in the epidermis. J Investig Dermatol 133:2191-2201. https://doi.org/10.1038/jid.2013.66

Grigoryev SA, Nikitina T, Pehrson JR, Singh PB, Woodcock CL (2004) Dynamic relocation of epigenetic chromatin markers reveals an active role of constitutive heterochromatin in the transition from proliferation to quiescence. J Cell Sci Dec $1117(\mathrm{Pt}$ 25):6153-6162 
Jackson DA, Iborra FJ, Manders EM, Cook PR (1998) Numbers and organization of RNA polymerases, nascent transcripts, and transcription units in HeLa nuclei. Mol Biol Cell 9:1523-1536

Kim MK, Yang S, Lee KH, Um JH, Liu M, Kang H, Park SJ, Chung JH (2011) Promyelocytic leukemia inhibits adipogenesis, and loss of promyelocytic leukemia results in fat accumulation in mice. Am J Physiol Endocrinol Metab 301:E1130-E1142. https://doi. org/10.1152/ajpendo.00092.2011

Kociucka B, Cieslak J, Szczerbal I (2012) Three-dimensional arrangement of genes involved in lipid metabolism in nuclei of porcine adipocytes and fibroblasts in relation to their transcription level. Cytogenet Genome Res 136:295-302. https://doi. org/10.1159/000338255

Kociucka B, Flisikowska T, Mroz D, Szczerbal I (2016) Expression of genes involved in lipid droplet formation (BSCL2, SNAP23 and COPA) during porcine in vitro adipogenesis. J Appl Genet 57:505-510. https://doi.org/10.1007/s13353-016-0350-9

Kuroda M, Tanabe H, Yoshida K, Oikawa K, Saito A, Kiyuna T, Mizusawa H, Mukai K (2004) Alteration of chromosome positioning during adipocyte differentiation. J Cell Sci 117:58975903. https://doi.org/10.1242/jcs.01508

Lammerding J, Fong LG, Ji JY, Reue K, Stewart CL, Young SG, Lee RT (2006) Lamins A and C but not lamin B1 regulate nuclear mechanics. J Biol Chem 281:25768-25780. https://doi. org/10.1074/jbc.M513511200

Lanctot C, Cheutin T, Cremer M, Cavalli G, Cremer T (2007) Dynamic genome architecture in the nuclear space: regulation of gene expression in three dimensions. Nat Rev Genet 8:104115. https://doi.org/10.1038/nrg2041

LeBlanc SE, Wu Q, Barutcu AR, Xiao H, Ohkawa Y, Imbalzano AN (2014) The PPARgamma locus makes long-range chromatin interactions with selected tissue-specific gene loci during adipocyte differentiation in a protein kinase A dependent manner. PLoS One 9:e86140. https://doi.org/10.1371/journal. pone. 0086140

Lin CY, Chen CY, Yu CH, Yu IS, Lin SR, Wu JT, Lin YH, Kuo PL, Wu JC, Lin SW (2016) Human X-linked intellectual disability factor CUL4B is required for post-meiotic sperm development and male fertility. Sci Rep 6:20227. https://doi.org/10.1038/ srep20227

Louveau I, Perruchot MH, Bonnet M, Gondret F (2016) Invited review: Pre- and postnatal adipose tissue development in farm animals: from stem cells to adipocyte physiology. Animal 10(11):1839-1847

Mao YS, Zhang B, Spector DL (2011) Biogenesis and function of nuclear bodies. Trends Genet TIG 27:295-306. https://doi. org/10.1016/j.tig.2011.05.006

Meaburn KJ (2016) Spatial genome organization and its emerging role as a potential diagnosis tool. Front Genet 7:134. https://doi. org/10.3389/fgene.2016.00134

Meaburn KJ, Misteli T (2007) Cell biology: chromosome territories. Nature 445:379-781. https://doi.org/10.1038/445379a

Melief SM, Zwaginga JJ, Fibbe WE, Roelofs H (2013) Adipose tissuederived multipotent stromal cells have a higher immunomodulatory capacity than their bone marrow-derived counterparts. Stem Cells Transl Med 2:455-463. https://doi.org/10.5966/ sctm.2012-0184

Moreno-Navarrete JM (2012) Adipocyte differentiation. In: Symonds ME (ed) Adipose tissue biology. Springer, New York, pp 17-38. https://doi.org/10.1007/978-1-4614-0965-6

Mudrak O, Tomilin N, Zalensky A (2005) Chromosome architecture in the decondensing human sperm nucleus. J Cell Sci 118:45414550. https://doi.org/10.1242/jcs.02581

Naetar N, Hutter S, Dorner D, Dechat T, Korbei B, Gotzmann J, Beug $\mathrm{H}$, Foisner R (2007) LAP2alpha-binding protein LINT-25 is a novel chromatin-associated protein involved in cell cycle exit. J Cell Sci 120(Pt 5):737-747

Ollion J, Cochennec J, Loll F, Escudé C, Boudier T (2013) TANGO: a generic tool for high-throughput 3D image analysis for studying nuclear organization. Bioinformatics 29(14):1840-1841. https:// doi.org/10.1093/bioinformatics/btt276

Osborne CS, Chakalova L, Brown KE, Carter D, Horton A, Debrand E, Goyenechea B, Mitchell JA, Lopes S, Reik W, Fraser P (2004) Active genes dynamically colocalize to shared sites of ongoing transcription. Nat Genet 36:1065-1071. https://doi.org/10.1038/ ng1423

Papantonis A, Cook PR (2013) Transcription factories: genome organization and gene regulation. Chem Rev 113:8683-8705. https://doi.org/10.1021/cr300513p

Pombo A, Dillon N (2015) Three-dimensional genome architecture: players and mechanisms. Nat Rev Mol Cell Biol 16:245-257 https://doi.org/10.1038/nrm3965

Reddy KL, Zullo JM, Bertolino E, Singh H (2008) Transcriptional repression mediated by repositioning of genes to the nuclear lamina. Nature 452:243-247. https://doi.org/10.1038/ nature 06727

Rosen ED, MacDougald OA (2006) Adipocyte differentiation from the inside out. Nat Rev Mol Cell Biol 7:885-896. https://doi. org/10.1038/nrm2066

Schneider R, Grosschedl R (2007) Dynamics and interplay of nuclear architecture, genome organization, and gene expression. Genes Dev 21:3027-3043. https://doi.org/10.1101/gad.1604607

Schoenfelder S, Sexton T, Chakalova L, Cope NF, Horton A, Andrews S, Kurukuti S, Mitchell JA, Umlauf D, Dimitrova DS, Eskiw CH, Luo Y, Wei CL, Ruan Y, Bieker JJ, Fraser P (2010) Preferential associations between co-regulated genes reveal a transcriptional interactome in erythroid cells. Nat Genet 42:53-61. https://doi. org/10.1038/ng.496

Sirri V, Urcuqui-Inchima S, Roussel P, Hernandez-Verdun D (2008) Nucleolus: the fascinating nuclear body. Histochem Cell Biol 129:13-31. https://doi.org/10.1007/s00418-007-0359-6

Skinner BM, Johnson EE (2017) Nuclear morphologies: their diversity and functional relevance. Chromosoma 126:195-212. https://doi. org/10.1007/s00412-016-0614-5

Solovei I, Kreysing M, Lanctôt C, Kösem S, Peichl L, Cremer T, Guck J, Joffe B (2009) Nuclear architecture of rod photoreceptor cells adapts to vision in mammalian evolution. Cell 137:356-368. https://doi.org/10.1016/j.cell.2009.01.052

Solovei I, Thanisch K, Feodorova Y (2016) How to rule the nucleus: divide et impera. Curr Opin Cell Biol 40:47-59. https://doi. org/10.1016/j.ceb.2016.02.014

Spector DL (2006) SnapShot: cellular bodies. Cell 127:1071. https:// doi.org/10.1016/j.cell.2006.11.026

Spurlock ME, Gabler NK (2008) The development of porcine models of obesity and the metabolic syndrome. J Nutr 138:397-402

Stachowiak M, Szczerbal I, Switonski M (2016) Genetics of adiposity in large animal models for human obesity-studies on pigs and dogs. Prog Mol Biol Transl Sci 140:233-270. https://doi. org/10.1016/bs.pmbts.2016.01.001

Stephens JM (2012) The fat controller: adipocyte development. PLoS Biol 10:e1001436. https://doi.org/10.1371/journal.pbio.1001436

Sun J, Fu S, Zhong W, Huang H (2013) PML overexpression inhibits proliferation and promotes the osteogenic differentiation of human mesenchymal stem cells. Oncol Rep 30:2785-2794. https://doi. org/10.3892/or.2013.2786

Sutherland H, Bickmore WA (2009) Transcription factories: gene expression in unions? Nat Rev Genet 10:457-466. https://doi. org/10.1038/nrg2592

Szczerbal I, Bridger JM (2010) Association of adipogenic genes with SC-35 domains during porcine adipogenesis. Chromosome Res 18:887-895. https://doi.org/10.1007/s10577-010-9176-1 
Szczerbal I, Foster HA, Bridger JM (2009) The spatial repositioning of adipogenesis genes is correlated with their expression status in a porcine mesenchymal stem cell adipogenesis model system. Chromosoma 118:647-663. https://doi.org/10.1007/ s00412-009-0225-5

van Koningsbruggen S, Gierlinski M, Schofield P, Martin D, Barton GJ, Ariyurek Y, den Dunnen JT, Lamond AI (2010) High-resolution whole-genome sequencing reveals that specific chromatin domains from most human chromosomes associate with nucleoli. Mol Biol Cell 21:3735-3748. https://doi.org/10.1091/mbc. E10-06-0508

Verstraeten VL, Renes J, Ramaekers FC, Kamps M, Kuijpers HJ, Verheyen F, Wabitsch M, Steijlen PM, van Steensel MA, Broers JL (2011) Reorganization of the nuclear lamina and cytoskeleton in adipogenesis. Histochem Cell Biol 135:251-261. https://doi. org/10.1007/s00418-011-0792-4

Volpi EV, Chevret E, Jones T, Vatcheva R, Williamson J, Beck S, Campbell RD, Goldsworthy M, Powis SH, Ragoussis J, Trowsdale J, Sheer D (2000) Large-scale chromatin organization of the major histocompatibility complex and other regions of human chromosome 6 and its response to interferon in interphase nuclei. J Cell Sci 113 (Pt 9):1565-1576
Walczak A, Szczepankiewicz AA, Ruszczycki B, Magalska A, Zamlynska K, Dzwonek J, Wilczek E, Zybura-Broda K, Rylski M, Malinowska M, Dabrowski M, Szczepinska T, Pawlowski K, Pyskaty M, Wlodarczyk J, Szczerbal I, Switonski M, Cremer M, Wilczynski GM (2013) Novel higher-order epigenetic regulation of the Bdnf gene upon seizures. J Neurosci Feb 6 33(6):25072511. https://doi.org/10.1523/JNEUROSCI.1085-12.2013

Weierich C, Brero A, Stein S, von Hase J, Cremer C, Cremer T, Solovei I (2003) Three-dimensional arrangements of centromeres and telomeres in nuclei of human and murine lymphocytes. Chromosome Res 11:485-502

Wijchers PJ, Geeven G, Eyres M, Bergsma AJ, Janssen M, Verstegen M, Zhu Y, Schell Y, Vermeulen C, de Wit E, de Laat W (2015) Characterization and dynamics of pericentromere-associated domains in mice. Genome Res 25:958-969. https://doi. org/10.1101/gr. 186643.114

Yerle-Bouissou M, Mompart F, Iannuccelli E, Robelin D, Jauneau A, Lahbib-Mansais Y, Delcros C, Oswald IP, Gellin J (2009) Nuclear architecture of resting and LPS-stimulated porcine neutrophils by 3D FISH. Chromosome Res 17:847-862. https://doi.org/10.1007/ s10577-009-9074-6 